\title{
PRODUÇÃO LEGISLATIVA E CONEXÃO ELEITORAL NAASSEMBLÉIA LEGISLATIVA DO ESTADO DO PARANÁ
}

\author{
Emerson Urizzi Cervi
}

\begin{abstract}
RESUMO
Este artigo insere-se na linha de trabalhos que tratam das relações entre a arena política legislativa e a arena política eleitoral, chamadas de "conexão eleitoral". O objetivo é analisar as interações entre essas duas arenas em um sistema de representação política sub-nacional: o legislativo estadual do Paraná. A partir da relação entre a produção legislativa individual dos deputados estaduais na $14^{a}$ Legislatura da Assembléia Legislativa do Paraná (ALEP) e o desempenho eleitoral dos que concorreram à reeleição, busca-se identificar possíveis interdependências entre atividade parlamentar individual e reeleição. Para isso, além dos resultados eleitorais dos candidatos à reeleição, que deram origem a uma tipologia de votação (se concentrada ou desconcentrada regionalmente) como variável dependente, são incluídos no modelo três conjuntos de variáveis explicativas. O primeiro é formado por variáveis sobre a posição política institucionalizada (bancada a que pertence; ideologia; partido político; ocupação de cargo na mesa; número de mandatos na ALEP; e posição sobre tema polêmico). O segundo aborda a visibilidade do mandato (número de aparições dos parlamentares no principal jornal diário do Estado e tipo de aparições). O terceiro grupo de variáveis explicativas diz respeito à produção legislativa individual propriamente dita (tipo de projeto de lei apresentado; abrangência geográfica do projeto de lei; abrangência social do projeto de lei; número de projetos apresentados; e número de projetos aprovados durante o mandato). A partir do cruzamento das variáveis que compõem o modelo em testes de independência de médias ou de regressões, o modelo analítico demonstra a existência de forte correlação entre votações concentradas regionalmente e maior possibilidade de reeleição. As variáveis explicativas sobre posição política e visibilidade do mandato mostraram-se fracas na explicação para tipo de votação, enquanto algumas variáveis sobre produção legislativa individual apresentaram alto índice de correlação com votação regionalizada e, por conseqüência, com a maior possibilidade de reeleição do parlamentar.
\end{abstract}

PALAVRAS-CHAVE: Conexão eleitoral; deputados estaduais; produção legislativa; Paraná.

\section{INTRODUÇÃO}

A relação entre atuação parlamentar e maior possibilidade de reeleição começou a ser e ainda é tradicionalmente tratada pela literatura como direta. Para isso foi criado um modelo explicativo chamado de "duas arenas" por Mayhew (1974) (cf. BOWLER, 2000). De acordo com esse modelo, os parlamentares, sempre movidos pelo interesse na reeleição e, portanto, na arena eleitoral, modelam seus comportamentos na arena legislativa para alcançar o objetivo principal que é reeleger-se e garantir a sua continuidade no Parlamento. Sendo assim, toda relação que o parlamentar tem com o seu partido ou sua bancada no poder Legislativo é uma necessidade imposta por melhores condições políticas para disputar e vencer eleições, não fa- zendo parte de uma estratégia política autônoma. A implicação desse modelo é que, havendo uma redução da importância dos partidos na arena eleitoral, estes também perdem funcionalidade no Parlamento, o que reduz os benefícios de um parlamentar em manter-se integrante de determinada linha de conduta partidária durante a legislatura. Sendo assim, a atuação do parlamentar seria muito mais individualizada e pouco responsável aos interesses da bancada a que faz parte.

A conceituação de “duas arenas" também enfraquece a importância dos partidos políticos no Parlamento. Essa tradição nasce com Downs (1957), que dá extrema importância nos processos eleitorais para as ações dos políticos, transformando-as em fator modulador das ações par- 
lamentares, a “conexão eleitoral”. Mayhew (1974) usa o termo "modelo de duas arenas" para explicar a importância da primeira arena, a eleitoral, sobre a segunda, que é legislativa, condicionando o comportamento dos parlamentares (PEREIRA \& MULLER, 2003, p. 736). Assim, a atuação dos políticos no poder Legislativo é uma conseqüência funcional da necessidade de obter-se votos em futuras eleições. Para Cain, Ferejohn e Fiorina (1987), como as ações dos parlamentares são orientadas para benefícios eleitorais e visam garantir a sua sobrevivência política, o parlamentar tenderá a dar mais atenção a seus redutos eleitorais, independente dos interesses coletivos do partido a que pertença ou das limitações institucionais.

Estudos empíricos, a partir da matriz teórica anterior, mostraram inconsistências nos pressupostos apresentados até então, o que levou os pesquisadores à criação de um modelo explicativo alternativo, denominado de "uma arena” Bowler (2000), partindo do pressuposto de serem fracos os elos entre as arenas eleitoral e legislativa. Antes dele, Gary Cox (1987) e Cox e McCubbins (1993) tentaram explicar o comportamento legislativo não apenas motivado pela conexão eleitoral, mas orientado por regras e procedimentos centralizadores da arena legislativa, que colocam os partidos em vantagem em relação às ações individuais dos políticos. De acordo com esse modelo, os parlamentares agem segundo os interesses de seus partidos e seguindo as determinações das lideranças no processo decisório, o que faz que a arena legislativa seja, em grande medida, desvinculada da arena eleitoral. Nesse caso, os partidos passam a dar acesso aos parlamentares ao processo decisório e solucionam o problema da ação coletiva no Parlamento (BOWLER, 2000). Assim, o Deputado começa a considerar como mais importantes as relações partidárias e de bancada, agindo coletivamente e respeitando as decisões da maioria. As implicações desse modelo são o possível enfraquecimento da reeleição como objetivo imediato do parlamentar na sua prática de representação dentro do Parlamento e o fato de que possíveis mudanças na arena eleitoral não afetariam diretamente a ação dos parlamentares no Legislativo. De acordo com o modelo de uma arena, os partidos resolvem as questões de ação coletiva no poder Legislativo ao oferecer uma estrutura institucional para escolhas e ao garantir comportamentos cooperativos dos deputados (PEREIRA \& MULLER, 2003). No Brasil, uma série de autores (FIGUEIREDO \& LIMONGI, 1995; 1997; 1999; 2000; 2002; MENEGHELLO, 1998; PEREIRA \& MULLER, 2000; AMORIM NETO \& SANTOS, 2001; AMORIM NETO, 2002) têm demonstrado a importância da centralização decisória no Congresso como explicação do comportamento parlamentar. Isso porque há evidências indicando que os parlamentares brasileiros comportam-se de forma consistente, disciplinada e em acordo com a indicação de seus líderes partidários.

Para o primeiro modelo existe uma "conexão eleitoral” direta, já no segundo, se houver alguma “conexão eleitoral”, ela será indireta. De maneira um pouco distinta em relação aos dois modelos anteriores, Pereira e Muller (2003) argumentam que ambos os modelos são parciais e incompletos para explicar o comportamento dos políticos e partidos dentro e fora do Parlamento brasileiro. Eles defendem que o sistema brasileiro não é totalmente descentralizado (duas arenas), mas também não é totalmente centralizado (uma arena), argumentando que ele condensa essas duas forças antagônicas. De um lado, as regras eleitorais, multipartidarismo e federalismo descentralizam o sistema político. De outro, regras internas de decisão no Congresso Nacional e distribuição de recursos políticos proporcionam uma grande centralização nesse mesmo sistema. Enquanto as regras eleitorais geram incentivos para o comportamento individual dos parlamentares, regras internas do Parlamento tornam o comportamento dos políticos dependente da lealdade a seus partidos, fortalecendo-os no Congresso. Pereira e Muller demonstram que os parlamentares, principalmente os da base do governo, cooperam com a agenda legislativa de votações, seguindo orientações de seus líderes para ter acesso a benefícios políticos controlados pelo Executivo. Esses benefícios devem ser usados na arena eleitoral para aumentar as chances de reeleição.

Neste artigo considera-se a existência de uma arena eleitoral descentralizada ou personalizada e uma arena legislativa parcialmente centralizada, pois os parlamentares, apesar de atuarem de maneira responsável junto à bancada ou partido, também podem - paralelamente - dispor de recursos legislativos para beneficiar seus redutos eleitorais, favorecendo a manutenção de sua carreira política. Para tanto, analisa-se a produção legislativa individual dos deputados estaduais do Paraná da $14^{\text {a }}$ Legislatura, entre 1999 e 2002, comparando com o desempenho eleitoral daqueles que se candidataram à reeleição no final do período. A 
hipótese a ser testada é a de que, apesar de leais às suas bancadas em temas polêmicos e de interesse do poder Executivo, a explicação para o desempenho eleitoral dos parlamentares pode ser encontrada na atuação individualizada prevista institucionalmente no Parlamento, pois é nos projetos de lei e mensagens de autoria do parlamentar que pode-se encontrar a origem da relação entre representante e representado durante todo o mandato.

O texto está dividido em três seções. Na primeira, são apresentadas algumas discussões sobre o comportamento individualizado do parlamentar brasileiro, dentre elas a alta taxa de renovação dos legislativos brasileiros quando comparada a de democracias consolidadas, o que leva a um desinteresse pela especialização em atividades legislativas mais técnicas; outra diz respeito ao sistema eleitoral brasileiro, pois a eleição por lista aberta para as disputas proporcionais de vagas no Legislativo leva a uma personificação das campanhas que passam a concentrar-se em regiões geográficas ou segmentos sociais. O accountability é maximizado quando os representados de determinado parlamentar encontram-se na mesma região ou segmento da sociedade. $\mathrm{O}$ grande número de trocas de partidos durante o mandato dificulta a identificação institucionalizada do parlamentar por parte do eleitor. Por fim, a visibilidade do Deputado pode ser considerada uma variável importante para a sua sobrevida política, pois há uma tendência da maioria dos eleitores brasileiros de analisar os candidatos, comparando as realizações deles, ao invés de avaliar individualmente o que cada um fez.

Na segunda seção do texto são apresentados resultados de testes estatísticos para o estabelecimento de um modelo com variáveis que sejam capazes de explicar o que realmente importa para a manutenção do Deputado em um cargo eletivo no poder Legislativo estadual paranaense a partir de dados obtidos da $14^{\mathrm{a}}$ Legislatura. Em primeiro lugar, é testado se o tipo de votação do parlamentar influencia a sua reeleição. Depois de agrupadas as votações por ordem de concentração geográfica em três níveis ${ }^{1}$ (regional, mista e disper-

1 A tipificação de votos dos parlamentares está baseada em resultados oficiais por município das eleições para a Assembléia Legislativa do Estado do Paraná (ALEP) de 1998 e 2002, fornecidos pelo Tribunal Regional Eleitoral do Paraná (TRE-PR). Foram selecionados os três mais votados em cada município, para a criação de um "índice de sa), testes estatísticos mostram uma alta correlação entre votação regionalizada e reeleição. Com base nisso, são testados cinco conjuntos de variáveis empíricas que poderiam explicar a votação regionalizada. A primeira delas diz respeito à carreira política do parlamentar, sendo composta por: partido a que pertenceu durante o mandato, posição do partido no espectro ideológico, bancada a que pertenceu na ALEP, número de mandatos como Deputado Estadual antes de 1998 e número de partidos políticos a que pertenceu durante o mandato. O segundo conjunto de variáveis é de caráter eleitoral, incluindo: coligação a que pertenceu em 2002, percentual de votos regionais em 1998 e 2002 e categoria de votação em 1998 e 2002. Outra variável a ser testada diz respeito à posição declarada no Parlamento em relação a temas polêmicos. Aqui, é usada a posição de cada parlamentar em relação ao projeto de lei que autorizava a privatização da Copel, Companhia de Energia do Paraná, que foi o principal mobilizador da opinião pública paranaense em

presença regional” dos deputados. Nesse primeiro momento não interessava o número de votos individual, mas a colocação do candidato na preferência dos eleitores de cada município. O mais votado no município recebeu peso três, o segundo colocado recebeu peso dois e o terceiro, peso um. Em seguida os valores foram agregados por mesorregiões, que passaram a ser a unidade de análise. A divisão geográfica do Estado por mesorregiões adotada é a definida pelo Instituto Brasileiro de Geografia e Estatística (IBGE) e pelo Instituto Paranaense de Desenvolvimento Econômico e Social (Ipardes). O Paraná está dividido em dez mesorregiões e como elas apresentam diferentes números de municípios, considerando que o índice parte do desempenho municipal dos candidatos, foi preciso normalizar os dados agregados pelo total de municípios. A vantagem da normalização, além de equiparar o desempenho regional dos deputados em todo o Estado, é que ela permite analisar os dados de maneira quantitativa. O resultado final é um índice de presença regional que varia de "muito baixa”, "baixa”, "média”, "alta” e "muito alta” nas eleições de 1998 e 2002. Para identificar se um parlamentar tem votação "regional”, "mista” ou "dispersa" foram somados os votos obtidos pelos deputados nas três primeiras colocações de cada município e o resultado foi comparado com o total da votação de cada Deputado. Se a soma dos votos obtidos entre os três mais votados em cada município ficar entre zero e 33,33\% do total, esse parlamentar é considerado como tendo votação “dispersa”, ou seja, não apresenta relevância em nenhuma região específica. Normalmente deputados que são comunicadores, representantes religiosos ou de categorias profissionais específicas costumam apresentar votação “dispersa” em todo o Estado. Se os votos regionais ficarem entre 33,34\% e 66,66\%, o Deputado é considerado como tendo votação "mista”. Se o total de votos regionais ultrapassar $66,67 \%$ da votação geral, o político é considerado com votação "regional”. 
relação à Assembléia Legislativa durante o período em análise. Também é testada a produção legislativa individual dos parlamentares por meio da categorização dos projetos de lei apresentados por eles em função da abrangência social ${ }^{2}$ (se o projeto é individual, segmentado ou de abrangência geral), da abrangência geográfica ${ }^{3}$ (se tem impacto muni- cipal, regional ou estadual) e por tipo de projeto ${ }^{4}$, se é de Utilidade Pública, Homenagem ou Autorizatório. A título de indicação sobre o volume total da produção legislativa individual dos deputados paranaenses, as tabelas a seguir sumarizam-na por abrangência social, geográfica e por tipo de projetos de lei durante a $14^{\mathrm{a}}$ Legislatura na ALEP.

QUADRO 1-PRODUÇÃO LEGISLATIVAPOR ABRANGÊNCIA GEOGRÁFICA

\begin{tabular}{|c|c|c|c|}
\hline \multirow[t]{2}{*}{ ABRANGÊNCIA GEOGRÁFICA } & \multicolumn{2}{|c|}{ PROJETOS } & \multirow[t]{2}{*}{ PERCENTUAL AGREG ADO } \\
\hline & N. & 㽞 & \\
\hline Municipal Centro & 137 & 5,33 & \multirow{4}{*}{42,83} \\
\hline Municipal OestelSul & 263 & 10,23 & \\
\hline Municipal Metropolitana & 303 & 11,78 & \\
\hline Municipal Norte & 373 & 14,50 & \\
\hline Regional Centro & 94 & 3,65 & \multirow{4}{*}{12,51} \\
\hline Regional OesteiSul & 72 & 2,80 & \\
\hline Regional Metropolitana & 33 & 1,28 & \\
\hline Regional Norte & 97 & 3.77 & \\
\hline Estadual & 1200 & 46,66 & 44,66 \\
\hline Total & 2572 & 100,00 & 100,00 \\
\hline
\end{tabular}

Do total de projetos de lei apresentados pelos parlamentares paranaenses durante a $14^{\mathrm{a}}$ Legislatura, 44,6\% foram de abrangência estadual, 42,8\% de abrangência municipal e apenas $12,5 \%$ de abrangência regional, o que indica uma atenção maior destinada a projetos ou de grande abrangência ou muito localizados.

QUADRO 2 - PRODUÇÃO LEGISLATIVA POR ABRANGÊNCIA SOCIAL

\begin{tabular}{|l|c|c|}
\hline ABRANGÉNCIA SOCIAL & \multicolumn{2}{|c|}{ PROJETOS } \\
\cline { 2 - 3 } & $\boldsymbol{N}$. & $\%$ \\
\hline Individual & 118 & 4,6 \\
Segmentado & 1993 & 77,5 \\
Geral & 461 & 17,9 \\
Total & 2572 & 100,0 \\
\hline
\end{tabular}

FONTE: Núcleo de Pesquisa em Sociologia Política Brasileira $(\mathrm{s} / \mathrm{d})$.

\footnotetext{
2 A abrangência social do projeto de lei leva em conta o número de pessoas que sofrerão impacto direto com a aprovação da lei proposta dentro de determinada área de abrangência geográfica. Exemplo de projeto individual é a proposta de cidadania honorária. Projeto segmentado pode ser uma proposta que diga respeito a determinada atividade econômica específica ou entidade. Projeto geral tem potencial impacto sobre todos os paranaenses de maneira equivalente.

3 A abrangência geográfica de um projeto de lei leva em conta a área de impacto direto da proposta. Esse impacto pode ser específico a um município, quando municipal, a uma região específica, quando regional, ou a todo o estado, quando estadual.
}

Ainda que localizados municipalmente ou tendo como abrangência todo o Estado, a grande maioria das propostas individuais dos parlamentares atingia segmentos específicos da sociedade, pois $77,5 \%$ das propostas tiveram abrangência social segmentada, contra 17,9\% de abrangência geral e apenas 4,6\% de abrangência estadual.

QUADRO 3 -PRODUÇÃO LEGISLATIVAPOR TIPO DE PROJETO INDIVIDUAL

\begin{tabular}{|l|c|c|}
\hline \multirow{2}{*}{ TIPO DE PROJETO } & \multicolumn{2}{|c|}{ PROJETOS } \\
\cline { 2 - 3 } & $\boldsymbol{N}$ & \multicolumn{1}{|c|}{ 品 } \\
\hline Utilidade Pública & 1025 & 64,96 \\
Homenagem & 131 & 8,30 \\
Autorizatório & 422 & 26,74 \\
Total & 1578 & 100,00 \\
\hline
\end{tabular}

Tonte: Núcleo de Pesquisa em Sociologia Política Brasileira (s/d).

OTA:

4 Projetos de lei de utilidade pública são aqueles que declaram de utilidade pública associações, entidades e instituições de modo geral, que passam a gozar de benefícios do Executivo Estadual e maior acesso a políticas públicas. Projetos de homenagem são aqueles que homenageiam pessoas ou entidades por meio da concessão de títulos honoríficos ou nomes de logradouros públicos tais como órgãos estaduais, rodovias, hospitais, prédios públicos etc. Projetos autorizatórios são, obrigatoriamente, de origem de um Deputado ou do poder Legislativo, e têm por finalidade autorizar o poder Executivo a realizar algum investimento, obra ou prestar qualquer outro serviço ou ação. Esse tipo de projeto de lei foi extinto na $15^{\mathrm{a}}$ Legislatura em função de sua pouca utilidade, visto que o Executivo raramente realizava as obras ou serviços "autorizados" por meio de um projeto de lei de um parlamentar. 
O Quadro 3 mostra um subconjunto dos projetos apresentados, pois desconsidera os projetos de lei com temáticas próprias, levando em conta apenas aqueles com exclusiva finalidade política. Quanto a esses três principais tipos de projetos individuais, quase $65 \%$ foram de utilidade pública, outros $26,7 \%$ autorizatórios e apenas $8,3 \%$ como homenagens. Essas três primeiras tabelas indicam como foi o conjunto da produção individual dos parlamentares paranaenses na $14^{\text {a }}$ Legislatura, mostrando que houve uma tendência equivalente entre as abrangências geográficas municipal e estadual; a abrangência social segmentada prevaleceu e houve maior produção de projetos de utilidade pública. As variações de produção dos diferentes tipos de projetos de lei individuais serão testadas com o desempenho eleitoral dos deputados que se candidataram à reeleição para identificação de possíveis relações entre a atividade parlamentar e os votos obtidos.

Outro conjunto de variáveis empíricas a ser testado com o tipo de votação obtida pelo parlamentar na candidatura à reeleição ao cargo diz respeito à visibilidade das ações do parlamentar. Para tanto são usadas informações sobre a cobertura dos parlamentares realizada pelo principal jornal diário do Paraná, Gazeta do Povo. Fazem parte desse conjunto de variáveis o número de citações que cada parlamentar teve no jornal durante a legislatura, o percentual de citações positivas e negativas no jornal e a diferença entre os percentuais positivo e negativo dos parlamentares no jornal. Com isso pretende-se criar um modelo estatístico que explique a votação regionalizada dos parlamentares em 2002 e, por conseqüência, a maior possibilidade de reeleição.

A terceira parte do texto apresenta as conclusões gerais a partir dos testes de correlação entre variáveis que indicam a produção individual do parlamentar, tipo de votação obtida na disputa pela reeleição e resultado eleitoral; além de, à luz dos dados empíricos obtidos nesse estudo de caso, pontuar o que é possível identificar como válido para o sistema legislativo subnacional brasileiro dos modelos de duas arenas ou uma arena a partir de um estudo de caso.

\section{O PARLAMENTAR: ENTRE PERSONALIZA- ÇÃO ELEITORAL E CENTRALIZAÇÃO LEGIS-LATIVA}

A existência de diferenças ${ }^{5}$ na estrutura de representação parlamentar de países europeus - em que os modelos de "duas arenas" e "uma arena" foram concebidos - em relação ao sistema de representação ${ }^{6}$ subnacional no Brasil torna necessário considerar as particularidades do sistema de representação brasileiro que não estão contempladas na discussão original. Por conta disso, tornase pertinente a hipótese de que a atuação parlamentar na ALEP apresenta características que mesclam os dois modelos já apresentados. Quando é permitida a atuação individual, o parlamentar utiliza-a para beneficiar diretamente os seus eleitores (pork barrel ${ }^{7}$ ), por meio de projetos de lei regionalizados, moções para a criação de entidades públicas a instituições de sua região, indicações de cidadania honorária etc. Porém, nos temas relacionados à formulação de políticas públicas mais amplas, para ter algum nível de influência nos resultados, o parlamentar precisa agir coletiva e disciplinadamente em relação a sua bancada. Pois isso poderá garantir outros tipos de ganhos - por meio de decisões do estado - para o conjunto dos eleitores. Deve-se considerar também que no Brasil há uma grande concentração de poder decisório sobre políticas públicas na esfera do poder Executivo. Mesmo que as decisões do chefe do Executivo sejam contrárias aos interesses dos representados, o parlamentar mantém a disciplina, pois o sistema eleitoral proporcional de votos garante-lhe a possibilidade de grande permeabilidade em busca de "novos" representados a cada eleição. Sem contar o necessário bom relacionamento com o Executivo para a distribuição de pork barrel às regiões de abrangência da representação do parlamentar - novas ou antigas.

Pode-se perceber que o modelo das duas arenas considera que os parlamentares têm como principal meta a reeleição; hipótese que se justifica para a análise da US House of Representatives,

\footnotetext{
5 Representação majoritária por distrito, por exemplo.

6 Proporcional por colégio eleitoral.

7 Pork e pork barrel são usados aqui como sinônimos de verbas governamentais para melhoramentos locais com fins
} eleitorais. 
onde a possibilidade de reeleição é muito alta. Porém, as taxas de retorno à Câmara Federal no Brasil e às Assembléias Legislativas estaduais são bem menores que as norte-americanas, ficando entre $40 \%$ e $50 \%$ nas últimas duas décadas (AMES, 2000). Isso significa que em cada nova legislatura, cerca de metade dos deputados é estreante. Essas taxas de renovação são mais altas em representações de regiões desenvolvidas como sul e sudeste, o que faz que as representações dessas áreas apresentem baixo nível de senhorio (AMES, 2000).

No Paraná, a renovação bruta da bancada ${ }^{8}$ na Assembléia Legislativa ficou próxima dos índices da Câmara Federal entre 1982 e 2002, chegando a $83 \%$ em 1986 e nunca menor que 45\%. De maneira geral, esses valores seguem a média das renovações eleitorais em todos os legislativos estaduais no mesmo período (SANTOS, 2002). Uma das questões debatidas na literatura é por que existe uma renovação tão alta no sistema legislativo nacional e subnacional brasileiro? Segundo Ames, alguns deputados desistem de concorrer pois sabem que não serão reeleitos. Outros optam por cargos eletivos no poder Executivo, em que, como prefeitos, consegue-se exercer maior controle sobre os programas e recursos públicos. Há ainda os que assumem trabalhos burocráticos no poder público como forma de aumentar sua clientela antes de voltar à disputa por cargos eletivos. Mas mesmo aqueles que concorrem à reeleição têm uma alta taxa de rejeição (AMES, 2000).

Elevados índices de renovação indicam a existência de riscos para a análise de casos brasileiros ao considerar-se automaticamente a hipótese de estabilidade sugerida a partir da dinâmica da Câmara dos Deputados dos Estados Unidos (US House of Representatives), em que a reeleição é a primeira meta do político eleito. Uma das consequiências das altas taxas de renovação é que os legisladores brasileiros passam a ter uma expectativa de carreira curta. A questão é saber em que medida essa expectativa afeta suas motivações e comportamentos, por exemplo, levando-os a uma atuação mais personalista e menos voltada para as questões da técnica legislativa. Por que deputados fariam um esforço para adquirir habilidades políticas se sabem que suas probabilidades de continuar na carreira não são tão altas como em

8 A renovação bruta é obtida computando-se o número total de representantes novos em uma legislatura, comparado à composição da legislatura anterior. outros países (idem)? A resposta a esse questionamento levaria a uma tendência de investir-se pouco na especialização do trabalho e de concentrar os esforços no envio de pork a suas regiões de representação, nos casos em que a meta é a reeleição. Porém, a concentração em porks tradicionais não deve ser automática na atividade do poder Legislativo; há também atenção especial a apresentação de propostas, tais como projetos de lei. Entre 1989 e 1991 os deputados federais brasileiros apresentaram 6,6 mil projetos de lei. Apenas 43 foram aprovados e a maioria não saiu das comissões. Ames (idem) conclui que os deputados apresentam projetos de lei não com a intenção de vê-los aprovados, mas porque querem distribuir cópias das propostas aos eleitores como forma de comprovação de serviço prestado.

Outro fator que pode modelar ações e comportamentos parlamentares é o sistema partidário. As regras eleitorais no Brasil geram uma relação entre partidos fracos e deputados individualistas, considerados aqui como aqueles que possuem bases eleitorais estabelecidas geograficamente ou em segmentos sociais bem definidos. Em sistemas eleitorais majoritários que elegem um representante por distrito eleitoral, votar em um partido é necessariamente votar em um candidato. Já nos sistemas de representação proporcional de lista existem diversas maneiras de definir quais candidatos ocuparão as vagas obtidas pelo partido. No Brasil temos a lista aberta, em que os partidos apresentam um conjunto de candidatos sem ordem de preferência e os eleitores decidem votar em um candidato ou partido e as vagas obtidas são ocupadas pelos mais votados (NICOLAU, 2002). Esse sistema de lista aberta estimula a predominância da reputação individual em detrimento do partido (cf. CAREY \& SHUGART, 1995). Os candidatos organizam suas campanhas independentemente dos partidos, e como o desempenho do partido depende do sucesso dos candidatos, os diretórios regionais preferem incluir nas listas indivíduos populares em seus segmentos sociais em detrimento dos envolvidos em atividades partidárias, como demonstrado por Manin (1995) quando caracteriza a "democracia de públicos”. Além disso, o processo de votação reforça a idéia do personalismo. O eleitor não recebe informações suficientes sobre coligações ou forma de distribuição de cadeiras (NICOLAU, 2002).

Além das regras eleitorais, as trocas de legenda durante o mandato também dificultam a identifica- 
ção partidária. A mudança de partido no Brasil vem sendo comum desde a redemocratização em 1985 (MELO, 2000). O fenômeno atinge o conjunto de partidos políticos e afeta todos os níveis do sistema representativo (federal, estadual e municipal). O número de deputados que abandonaram o partido pelo qual foram eleitos nas quatro legislaturas da Câmara Federal do período democrático é impressionante: dos 2016 representantes eleitos em 1986, 1990, 1994 e 1998, 621 (30,8\%) trocaram de partido ao longo da legislatura, alguns deles mais de uma vez (NICOLAU, 2002). Como pode-se ver no Quadro abaixo, a ALEP não é exceção à regra da alta migração partidária. Dos doze partidos que tiveram representação na ALEP durante a legislatura de 1999 a 2002, apenas dois (16,6\%), o partido Socialista Brasileiro (PSB) e o Partido dos Trabalhadores (PT), não apresentaram variação no número de componentes da bancada em toda a legislatura.

\section{QUADRO 4-BANCADAS PARTIDÁRIAS NAALEP}

\begin{tabular}{|l|c|c|c|c|c|c|}
\hline PARTIDO & ELEIÇÃO & $\mathbf{1 9 9 9}$ & $\mathbf{2 0 0 0}$ & $\mathbf{2 0 0 1}$ & $\mathbf{2 0 0 2}$ & MÉDIA ANUAL \\
\hline PDT & 3 & 3 & 3 & 2 & 6 & 3,5 \\
PFL & 12 & 10 & 9 & 9 & 9 & 9,25 \\
PL & - & 2 & 1 & 2 & 2 & 1,75 \\
PMDE & 7 & 7 & 7 & 7 & 8 & 7,25 \\
PPB & 8 & 7 & 5 & 4 & 6 & 5,5 \\
PSB & 2 & 2 & 2 & 2 & 2 & 2 \\
PSC & 1 & 2 & 1 & 1 & 1 & 1,25 \\
PSDE & 6 & 7 & 7 & 6 & 8 & 7 \\
PT & 4 & 4 & 4 & 4 & 4 & 4 \\
PTB & 11 & 10 & 10 & 11 & 5 & 9 \\
PSL & - & - & 3 & 3 & 3 & 2,25 \\
PST & - & - & 2 & 2 & - & 1 \\
Sem partido & - & - & - & 1 & - & 0,25 \\
TOTAL & 54 & 54 & 54 & 54 & 54 & 54 \\
\hline
\end{tabular}

FONTE: Núcleo de Pesquisa em Sociologia Política Brasileira (s/d) e dados primários das atas de sessões ordinárias da ALEP organizados pelo autor.

NOTAS: 1. os números de deputados por partido foram tomados em fevereiro de cada ano.

2. PDT: Partido Democrático-Trabalhista; PFL: Partido da Frente Liberal; PL: Partido Liberal; PMDB: Partido do Movimento Democrático Brasileiro; PPB: Partido Progressista Brasileiro; PSC: Partido Social-Cristão; PSDB: Partido da Social-Democracia Brasileira; PTB: Partido Trabalhista Brasileiro; PSL: Partido Social-Liberal; PST: Partido Social-Trabalhista.

As altas variações nas bancadas coincidem com o grande número de parlamentares que migraram de partido na legislatura. Dos 59 parlamentares que passaram pela ALEP no período, 25 (42,4\%) trocaram de partido pelo menos uma vez. Houve cinco $(8,5 \%)$ deputados que trocaram duas vezes de legenda e um (1,6\%), que passou por três partidos nos quatro anos de mandato. A baixa identidade partidária e independência dos candidatos durante as eleições geram condições favoráveis ao personalismo na ação parlamentar e concentração de esforços para uma representação regional pode significar a maximização de ganhos individuais.
Um eleitorado fragmentado reduz a accountability $^{9}$. Deputados com votação concentrada regionalmente - representando eleitores que demandam altos níveis de benefícios locais - têm poucas razões para apoiar partidos cujos líderes esperam por votações em conjunto nas questões que vão além do espaço local mais imediato, ou seja, aquelas que podem interessar de maneira difusa eleitores de todas as regiões do estado. Mas até que ponto pode-se dizer que a distribuição geográfica do apoio eleitoral influencia as ações dos parlamentares? Em primeiro, a

\footnotetext{
9 Na versão de Powell Jr. (2000) do accountability model, as eleições são o momento apropriado para o eleitor punir ou recompensar seus representantes.
} 
hegemonia eleitoral em determinada região demonstra uma habilidade do Deputado de obter altas percentagens de votos em municípios atendidos pelo trabalho de representação política. Deputados regionais são mais fortes em regiões pouco desenvolvidas e em áreas rurais, mas essa hegemonia é impossível de ser mantida se não houver um retorno à elite econômica e social da comunidade representada. Aliado a isso, os deputados regionais tendem a ser a sustentação do poder do Executivo em suas áreas de votação. A dinâmica da representação torna os deputados mais aptos a receberem crédito pelo pork enviado aos municípios, e quando isso acontece eles passam a trabalhar mais para enviar pork a suas regiões. Como no Brasil é o poder Executivo que domina os programas de pork barrel, boas relações com o chefe do Executivo e seu corpo de ministros ou secretários de estado são uma necessidade para deputados regionalistas (AMES, 2000, p. 108).

Ao mesmo tempo em que o sistema representativo incentiva a atuação parlamentar personalista, os eleitores desenvolvem mecanismos para a escolha dos representantes não partidariamente. Assim, o acompanhamento da atividade de um parlamentar e a decisão de reconduzi-lo ou não ao cargo também são feitos de maneira personalizada.

A avaliação do trabalho de um parlamentar em bases personalizadas pode ocorrer de duas maneiras: a primeira pressupõe que o eleitor monitore exclusivamente o desempenho daquele em quem votou; na segunda, o eleitor não acompanha necessariamente o parlamentar em quem votou, mas o que durante o mandato conseguiu de alguma maneira chamar a sua atenção (NICOLAU, 2002, p. 225). Como a maioria dos eleitores brasileiros diz não se lembrar em quem votou para Deputado nas eleições anteriores quando consultados em pesquisas de opinião pública, é provável que as avaliações de primeiro tipo sejam feitas por um percentual reduzido do eleitorado. O que permite especular sobre a importância da visibilidade do parlamentar no decorrer do seu mandato. Como apontado anteriormente, o sistema eleitoral brasileiro estimula a atuação personalizada e não-partidária. Mas há limites e dificuldades para a avaliação personalista retrospectiva dos candidatos por parte dos eleitores.

Portanto, temos três fatores identificados no sistema de representação legislativa brasileiro que favorecem a atuação personalista. Em primeiro lugar, os altos índices de renovação eleitoral; em segundo, o sistema eleitoral que leva à atuação individualizada na arena eleitoral, gerando um padrão de representação pessoal e regionalizada; e por fim, os instrumentos desenvolvidos pelos eleitores para julgar a atuação dos representantes antes de decidir em quem votar.

\section{ATUAÇÃO POLÍTICA, PRODUÇÃO LE- GISLATIVA E VISIBILIDADE PARLAMEN- TAR}

Dos 54 parlamentares que terminaram o mandato na ALEP em 2002, apenas quatro não se candidataram à reeleição para o mesmo cargo (dois candidataram-se a Deputado Federal, um a Senador e um a vice-Governador). Como o nosso objetivo é identificar as variáveis explicativas para a reeleição do parlamentar, só serão consideradas as informações relacionadas aos 50 parlamentares que terminaram o mandato e concorreram à reeleição em 2002. Desses, 30 (60\%) foram reeleitos e 20 (40\%) não conseguiram reeleger-se. Como demonstra o Quadro 5, do total, 40\% dos parlamentares analisados tiveram votações regionalizadas, $32 \%$ votação dispersa e $28 \%$ votação mista. No entanto, considerando apenas os reeleitos, a votação regional ganha importância, passando para $56,6 \%$ contra $23,4 \%$ com votos mistos e apenas $20 \%$ com votação dispersa, indicando uma maior presença, dentre os reeleitos, de parlamentares com votações concentradas em determinadas regiões geográficas. Percebe-se que o maior número de reeleitos encontra-se em votação regionalizada, sendo 17 dos 30. Além disso, na votação regionalizada também está o menor número de parlamentares não reeleitos, com apenas três entre os 20.

QUADRO 5 - SITUAÇÃO EM 2002 POR TIPO DE VOTAÇÃO

\begin{tabular}{|c|c|c|c|c|c|}
\hline & & \multicolumn{3}{|c|}{ CA TEG ORIA DE VOTAÇÃO EM 02} & \multirow{2}{*}{ TOTAL } \\
\hline & & $\begin{array}{c}\text { VO TOS } \\
\text { RE GIONALIZADOS }\end{array}$ & $\begin{array}{l}\text { votos } \\
\text { MSTOS }\end{array}$ & $\begin{array}{c}\text { VOTOS } \\
\text { DISPERSOS }\end{array}$ & \\
\hline $\begin{array}{l}\text { Situação em } \\
2002 \\
\text { Total }\end{array}$ & $\begin{array}{l}\text { Reeleito } \\
\text { Nẫo reeleito }\end{array}$ & $\begin{array}{c}17(56,6 \%) \\
3(15 \%) \\
20(40 \%)\end{array}$ & $\begin{array}{c}7(23,4 \%) \\
7(35 \%) \\
14(28 \%)\end{array}$ & $\begin{array}{c}6(20 \%) \\
10(50 \%) \\
16(32 \%)\end{array}$ & $\begin{array}{l}30(100 \%) \\
20(100 \%) \\
50(100 \%)\end{array}$ \\
\hline
\end{tabular}


O teste de independência de quiquadrado ${ }^{10}$, mostrado no Quadro 6, entre as duas variáveis - situação em 2002 (se reeleito ou não) e tipo de votação (regional, mista ou dispersa) -, comprova a existência de diferenças estatisticamente significativas entre aqueles que são reeleitos e o tipo de votação que tiveram, com alto nível de significância $(0,010)$. Assim como o teste de correlação de Spherman, Quadro 7, também indica uma relação positiva entre as duas variáveis, com nível de significância de 0,002 e coeficiente de correlação de $41,9 \%$, ou seja, quando mais próximo de votos regionalizados estiver o parlamentar, maiores as chances de reeleição. Isso resulta em um coeficiente de determinação de $17,5 \%$, ou seja, quase um quinto da reeleição do parlamentar foi determinado pelo tipo de votação que ele recebeu.

QUADRO 6 - TESTE DE INDEPENDÊNCIA: SITUAÇÃO/2002 E TIPO DE VOTAÇÃO

\begin{tabular}{|l|c|c|c|}
\hline & VALOR & GRAUS DE LIBERDADE & NíVEL DE SIGNIFICÂNCIA \\
\hline Qui-quadrado de Pearson & 9,167 & 2 & 0,010 \\
\hline FONTE: Núcleo de Pesquisa em Sociologia Política Brasileira (s/d).
\end{tabular}

QUADRO 7 - CORRELAÇÃO DE SPHERMAN - SITUAÇÃO/2002 E TIPO DE VOTAÇÃO

\begin{tabular}{|l|c|c|}
\hline & VALOR & NÍVEL DE SIGNIFICÂNCIA \\
\hline Correlaçẫo de Spherman & 0,419 & 0,002 \\
\hline
\end{tabular}

Para confirmar a importância da votação regionalizada na reeleição dos parlamentares, os resultados abaixo mostram o teste de diferenças de médias (Anova) do percentual de votos regionais em 2002 dos candidatos à reeleição uma variável contínua -, tendo como fator de teste a reeleição ou não do parlamentar.

QUADRO 8 - TESTE (ANOVA): PERCENTUAL DE VOTOS REGIONAIS EM 2002

\begin{tabular}{|l|c|c|}
\hline & GRAUS DE LIBERDADE & NŃVEL DE SIGNIF ICÂNCIA \\
\hline Resultados entre os grupos & 1 & 0,003 \\
\hline
\end{tabular}

FONTE: Núcleo de Pesquisa em Sociologia Política Brasileira (s/d).

NOTA: Fator: ter sido ou não reeleito em 2002.

Esses resultados comprovam a importância que a votação regionalizada teve para a reeleição na Assembléia Legislativa do Paraná em 2002, pois também no Anova há um alto nível de significância $(0,003)$, indicando a existência de diferenças nas médias de percentuais de votações regionais entre aqueles que se reelegeram e os que não foram reeleitos, inclusive quando considera-se o percentual de votos regionalizados. Até aqui, todos os resultados apontam para a importância da votação concentrada em determinada região do estado como explicação para a reeleição, indican-

10 O teste de qui-quadrado é um teste de livre distribuição. Aqui, ele serve para verificar se há ou não associação entre do a existência de uma subdistritalização eleitoral na prática para os parlamentares que pretendem reeleger-se, pois os resultados mostram que os candidatos que conseguem sucesso nas eleições concentram suas campanhas em determinadas áreas do estado.

Em consonância com os objetivos aos quais se propõe este texto, resta saber se há alguma relação entre a atividade parlamentar individual do Deputado e o tipo de desempenho eleitoral apresentado por ele ao final do mandato. Na hipótese

duas variáveis, comparada a dois ou mais grupos, tais como ter sido ou não reeleito (dois grupos) ou tipo de votação: regional, mista ou dispersa (três grupos). 
de que haja uma ligação entre a atividade parlamentar e o tipo de votação, será possível indicar uma relação direta entre as duas arenas, legislativa e eleitoral. Caso contrário, se a produção legislativa individual não tiver nenhuma relação com o tipo de votação, ficará evidenciada a dissociação entre ambas variáveis. Nesse caso, tornar-se-á necessário buscar explicações a partir de outros conjuntos de variáveis disponíveis, além da produção legislativa individual, tais como variáveis de caráter político, de posicionamento em relação a temas polêmicos e de visibilidade pública do Deputado.

A seguir são apresentados os resultados de significância em testes estatísticos das correlações entre três variáveis dependentes: "tipo de votação" (regional, mista ou dispersa), se "reeleito ou não" e o "total de votos em 2002”, com as variáveis independentes apresentadas no início do texto.

Quando correlacionadas, individualmente, com a variável dependente se "reeleito ou não" em 2002, poucas das vinte e oito variáveis independentes apresentam resultados estatisticamente significativos. É o caso das citações com valência negativa na Gazeta do Povo, que apresenta alta correlação com o fato do Deputado não ter sido reeleito. O coeficiente de determinação, nesse caso, é de 39,3\%, como mostra o Quadro 9. Todas as demais variáveis sobre visibilidade, de caráter político e a respeito de tema polêmico (privatização da Companhia Paranaense de Energia (Copel)) tiveram resultados estatisticamente não significativos. Entre as variáveis de atuação política, nenhuma se mostra estatisticamente significativa em relação à situação eleitoral em 2002. Por outro lado, algumas variáveis sobre a produção parlamentar individual apresentaram forte correlação com o fato de o parlamentar ter sido reeleito ou não. É o caso do percentual de projetos de lei de utilidade pública e de abrangência municipal, ambos com coeficiente de determinação de 8,1\%, que se mostram correlacionados direta e positivamente, ou seja, quanto maior o percentual desses projetos, maiores as chances do parlamentar ser reeleito. Já a apresentação de projetos autorizatórios e de abrangência estadual também apresentaram correlação estatisticamente significativa, porém, contrária à reeleição, ou seja, quanto maior o percentual de projetos autorizatórios ou de abrangência estadual apresentados pelo parlamentar, menor a possibilidade de reeleição. Os demais tipos de projetos não tiveram correlação linear significativa com a situação eleitoral em 2002. Aqui, mais uma vez, a correlação linear entre ter sido reeleito ou não com o percentual de votos regionais e com a categoria de votação mostrou-se altamente significativa, com coeficiente de determinação de 20,7\% para o percentual de votos regionais e de $17,6 \%$ para a categoria de votos em 2002. Ambos apontam para uma correlação linear entre concentração regional de votos e maior possibilidade de reeleição, confirmando o que havia indicado anteriormente o Quadro 6.

O que mais interessa do Quadro 9 neste momento da análise é que apenas duas variáveis de produção legislativa mostraram-se correlacionadas linearmente com a reeleição do Deputado: a apresentação de projetos de utilidade pública e a apresentação de projetos com abrangência municipal. Já a apresentação de projetos autorizatórios, de abrangência estadual e de citações negativas na Gazeta do Povo apresentaram correlação linear negativa, ou seja, quanto maiores seus percentuais, menores as chances de reeleição do parlamentar. As variáveis que quantificam a produção legislativa individual do parlamentar ("Total de projetos apresentados" e "Percentual de projetos aprovados") não apresentaram correlação consistente com o fato de o Deputado ter sido ou não reeleito, ou seja, o volume de produção individual teve impacto próximo a nulo para a decisão do voto nesse caso. 
QUADRO 9 - CORRELAÇÃO ENTRE REELEIÇÃO/02 E VARIÁVEIS EXPLICATIVAS

\begin{tabular}{|c|c|c|c|c|}
\hline \multicolumn{5}{|c|}{ CORRELAÇÃO NÃO-PARAMÉ TRICA (SPHERMAN) } \\
\hline $\begin{array}{l}\text { VARIÁVELL } \\
\text { DEPE HDENTE }\end{array}$ & VARIÁVEL INDEPENDENTE & \begin{tabular}{|l|} 
COEFICIE NTE \\
CORRE LAÇÄO
\end{tabular} & SIG. & $\begin{array}{l}\text { COEFICIENTE } \\
\text { DETERHAWAÇÃo }\end{array}$ \\
\hline \multirow{28}{*}{$\begin{array}{l}\text { Se reeleito ou } \\
\text { nắ em } 2002\end{array}$} & Bancada & 0,153 & 0,288 & 0,023 \\
\hline & Ideologia & 0,148 & 0,307 & 0,022 \\
\hline & Partido em que se elegeu em 1998 & 0,241 & 0,092 & 0,058 \\
\hline & Cargo na mesa & $-0,194$ & 0,178 & 0,038 \\
\hline & Número de mandatos & 0,131 & 0,363 & 0,017 \\
\hline & Número de Partidos & $-0,028$ & 0,845 & 0,001 \\
\hline & Posiçẫo Privatizaçẫo Copel & $-0,009$ & 0,952 & 0,000 \\
\hline & Coligaçẫo em 2002 & 0,155 & 0,283 & 0,024 \\
\hline & Citaçốes Gazeta do Pơo & 0,202 & 0,159 & 0,041 \\
\hline & Citaçổes Positivas GP & $-0,245$ & 0,087 & 0,060 \\
\hline & Citações Negativas GP & $-0,627^{* *}$ & $\mathbf{0 , 0 0 0}$ & 0,393 \\
\hline & Dif. Positivas e Negativas GP & 0,185 & 0,198 & 0,034 \\
\hline & Percentual Proj. Utilidade Pública & 0,284* & 0,044 & 0,081 \\
\hline & Percentual Proj. homenagem & $-0,126$ & 0,385 & 0,016 \\
\hline & Percentual Proj. Autorizatórios & $-0,343^{*}$ & 0,015 & 0,118 \\
\hline & Percentual Proj. Municipais & $\mathbf{0 , 2 8 4 ^ { * }}$ & 0,045 & 0,081 \\
\hline & Percentual Proj. Regionais & 0,033 & 0,822 & 0,001 \\
\hline & Percentual Proj. Estaduais & $-0,310^{*}$ & 0,029 & 0,096 \\
\hline & Percentual Proj. Individuais & 0,087 & 0,548 & 0,008 \\
\hline & Percentual Proj. Segmentados & 0,115 & 0,428 & 0,013 \\
\hline & Percentual Proj. Gerais & $-0,132$ & 0,362 & 0,017 \\
\hline & Percentual Proj. Aprovados & 0,212 & 0,139 & 0,045 \\
\hline & Percentual Proj. Rejeitados & $-0,202$ & 0,159 & 0,041 \\
\hline & Total Proj. Apresentados & $-0,010$ & 0,946 & 0,000 \\
\hline & Percentual de Votos Regionais 1998 & 0,147 & 0,308 & 0,022 \\
\hline & Categoria de Votos 1998 & $-0,139$ & 0,335 & 0,019 \\
\hline & Percentual de Votos Regionais 2002 & $0,455^{\star *}$ & 0,001 & 0,207 \\
\hline & Categoria de Votos 2002 & $-0,419^{\star \star}$ & 0,002 & 0,176 \\
\hline
\end{tabular}

FONTE: Núcleo de Pesquisa em Sociologia Política Brasileira (s/d).

NOTAS: 1. * Significativo a 0,05

2. ** Significativo a 0,01 .

Apesar de sugerir uma relação entre produção concentrada em determinados municípios do estado com a reeleição, os resultados do Quadro 9 não são suficientes para comprovar a relação direta entre tipo de produção legislativa individual com categoria de votação - se mais ou menos regionalizada - e, por conseqüência, com as chances de reeleição do parlamentar. Em outras palavras, eles indicam que há maior probabilidade de reeleição entre os deputados que apresentam projetos de lei dirigidos a comunidades específi- cas e, ao contrário, menores chances de reeleição para aqueles que apresentaram mais projetos de lei de abrangência estadual. Porém, não mostram se a produção legislativa mais local e menos estadual tem correlação com a obtenção de votos regionalizados na disputa pela reeleição a uma vaga no poder Legislativo. Até aqui, essa inferência pode ser feita apenas de maneira indireta. Para verificar a sua consistência será necessário realizar outros testes estatísticos, que deverão considerar, além do fato do parlamentar ter sido reeleito ou não, o tipo de votação obtida por ele. 
Para identificar se a atuação parlamentar individual segmentada geograficamente resulta em votação regionalizada, primeiro faz-se necessário um teste de independência por diferenças de médias dos percentuais de tipos de projetos de lei apresentados pelos parlamentares para dois fatores: categoria de votação em 2002, se regional, mista ou dispersa; e para o fato do candidato ter sido ou não reeleito. Fazendo uma análise dos resultados das diferenças de médias entre a atuação parlamentar individual é possível identificar, ainda que parcialmente, o mesmo padrão de relações mostrado pelos testes de correlação anteriores.

De acordo com o Quadro 10, nas diferenças de médias dos percentuais de projetos e tipo de votação, mostraram-se significativamente distintos os percentuais de projetos de abrangência municipal e estadual, com altos níveis de significância (0,000 em ambos os casos) e estatísticas $\mathrm{F}$ também altas, com 11,28 para projetos municipais e 13,85 para projetos estaduais. Ou seja, os grupos de votação regionalizada, mista ou dispersa apresentam médias distintas para esses dois tipos de projetos de lei apresentados. Quanto aos demais, não há diferença significativa. Em relação à situação eleitoral em 2002, apresentaram diferenças de médias estatisticamente significativas os percentuais de projetos de lei de utilidade pública, autorizatórios e de abrangência estadual, como já identificado no Quadro 6. Aqui, os resultados não foram tão altos como no fator anterior, com níveis de significância de 0,057 para projetos de utilidade pública, 0,052 para projetos de abrangência estadual e 0,008 para projetos autorizatórios. Isso significa que as diferenças de médias entre as variáveis estatisticamente significativas para o segundo fator não são tão fortes quanto às do primeiro. Ou seja, enquanto a produção legislativa individual relaciona-se diretamente com os votos obtidos, o fato de o Deputado ser ou não reeleito depende de outros fatores que vão além da própria votação.

QUADRO 10 - DIFERENÇA DE MÉDIAS PARA PRODUÇÃO LEGISLATIVAINDIVIDUAL, TIPO DE VOTAÇÃOE REELEIÇÃO

\begin{tabular}{|l|c|c|c|c|}
\hline F ATOR & VARIÁVEL & DF & F & SIG. \\
\hline $1^{\circ}$ Categoria de votaçẵo em 2002 & Percentual de projetos utilidade pública & 2 & 1,326 & 0,275 \\
& Percentual de projetos de homenagem & 2 & 1,918 & 0,158 \\
& Percentual de projetos autorizatórios & 2 & 0,171 & 0,843 \\
& Percentual de projetos municipais & 2 & $\mathbf{1 1 , 2 8 5}$ & $\mathbf{0 , 0 0 0}$ \\
& Percentual de projetos regionais & 2 & 0,830 & 0,442 \\
& Percentual de projetos estaduais & $\mathbf{2}$ & $\mathbf{1 3 , 8 5 7}$ & $\mathbf{0 , 0 0 0}$ \\
& Percentual de projetos individuais & 2 & 0,471 & 0,627 \\
& Percentual de projetos segmentados & 2 & 0,147 & 0,864 \\
& Percentual de projetos gerais & 2 & 0,210 & 0,811 \\
& Percentual de projetos utilidade pública & $\mathbf{1}$ & $\mathbf{3 , 7 8 9}$ & $\mathbf{0 , 0 5 7}$ \\
& Percentual de projetos de homenagem & 1 & 0,088 & 0,768 \\
& Percentual de projetos autorizatórios & $\mathbf{1}$ & $\mathbf{7 , 6 9 9}$ & $\mathbf{0 , 0 0 8}$ \\
& Percentual de projetos municipais & 1 & 3,709 & 0,060 \\
& Percentual de projetos regionais & 1 & 0,197 & 0,659 \\
& Percentual de projetos estaduais & $\mathbf{1}$ & $\mathbf{3 , 9 7 2}$ & $\mathbf{0 , 0 5 2}$ \\
& Percentual de projetos individuais & 1 & 0,776 & 0,383 \\
& Percentual de projetos segmentados & 1 & 0,084 & 0,773 \\
& Percentual de projetos gerais & 1 & 0,854 & 0,360 \\
\hline
\end{tabular}

FONTE: Núcleo de Pesquisa em Sociologia Política Brasileira (s/d).

No entanto, o teste de independência por diferença de médias indica apenas a existência de diferenças significativas entre distintos grupos; no caso, entre os deputados reeleitos ou não e entre aqueles que tiveram votação regional, mista ou dispersa. Ele não é capaz de indicar se existe al- 
gum tipo de correlação entre o fator e as variáveis explicativas, e, se existir, qual a intensidade e direção da relação. Para isso, aplica-se o teste de correlação linear de Spearman, transformando os fatores em variáveis dependentes e os tipos de projetos de lei apresentados em variáveis explicativas.

O resultado entre o tipo de atuação individual no Parlamento e o tipo de votação indica forte correlação entre a maior atenção dada pelo parlamentar a determinados tipos de projetos de lei e o tipo de votação obtida, se mais ou menos concentrada regionalmente. Em relação à categoria de votação, as duas variáveis que apresentam resultados estatisticamente significativos são o percentual de projetos municipais e o de projetos estaduais, como mostra o Quadro 10, porém, com o teste de correlação é possível identificar a intensidade e direção das relações. Percebe-se que elas são inversas. Enquanto a relação entre o percentual de projetos municipais e votação regionalizada está na mesma direção, com coeficiente de determinação de $30,1 \%$, a relação entre percentual de projetos de abrangência estadual e votação dispersa encontrase na em direção oposta, com coeficiente de determinação de 34,6\%, conforme mostra o Quadro 11. Isso significa que quanto maior o percentual de projetos com abrangência municipal, maior a possibilidade de obter uma votação regionalizada, assim como os maiores percentuais de projetos estaduais geram uma votação mais dispersa.

QUADRO 11 - CORRELAÇÃO LINEAR ENTRE PRODUÇÃO LEGISLATIVA INDIVIDUAL, TIPO DE VOTAÇÃO E REELEIÇÃO

\begin{tabular}{|c|c|c|c|c|}
\hline \multicolumn{5}{|c|}{ CORRELAÇÃO NÃOPARAMÉ TRICA (SPHERMAN) } \\
\hline $\begin{array}{l}\text { VARIÁVEL } \\
\text { DEPENDENTE }\end{array}$ & VARIÁVEL INDEPENDENTE & $\begin{array}{l}\text { COEFICIENTE } \\
\text { CORRELAÇẪo }\end{array}$ & SIG. & $\begin{array}{l}\text { COEFICIENTE } \\
\text { DETERMINAÇÃo }\end{array}$ \\
\hline \multirow{9}{*}{$\begin{array}{l}\text { Categoria de } \\
\text { votaçấo em } \\
2002\end{array}$} & Percentual projetos utilidade pública & 0,133 & 0,356 & 0,018 \\
\hline & Percentual projetos de homenagem & $-0,257$ & 0,072 & 0,066 \\
\hline & Percentual projetos autorizatórios & 0,050 & 0,732 & 0,003 \\
\hline & Percentual projetos municipais & $0,549^{* *}$ & 0,000 & 0,301 \\
\hline & Percentual projetos regionais & 0,267 & 0,061 & 0,071 \\
\hline & Percentual projetos estaduais & $-0,588^{* *}$ & 0,000 & 0,346 \\
\hline & Percentual projetos individuais & $-0,052$ & 0,719 & 0,003 \\
\hline & Percentual projetos segmentados & 0,001 & 0,995 & 0,000 \\
\hline & Percentual projetos gerais & 0,058 & 0,690 & 0,003 \\
\hline
\end{tabular}

FONTE: Núcleo de Pesquisa em Sociologia Política Brasileira (s/d).

NOTAS: 1. * Significativo a 0,05

2. ** Significativo a 0,01

A partir desses resultados de independência de médias e correlações tem-se subsídios para construir modelos explicativos pelo método de regressão linear para medir o peso das variáveis explicativas em conjunto, principalmente as que se referem à produção legislativa individual, sobre o volume de votos obtidos pelos candidatos à reeleição e sobre o percentual de votos regionalizados dos parlamentares ${ }^{11}$. O método de regressão linear permite, além de identificar os coeficientes de correlação e determinação, quantificar em unidades das variáveis, seja em número de votos ou em percentual de votos

11 Por tratar-se de uma regressão linear, todas as variáveis precisam ser contínuas. Por isso, a variável dependente regionalizados, a influência de cada variável explicativa para o modelo. Como já são conhecidos os coeficientes de correlação, de determinação e níveis de significância de testes anteriores, a seguir serão apresentados apenas os coeficientes das regressões lineares. São dois modelos. No primeiro, a variável dependente "Total de Votos em 2002”, foi testada com as variáveis explicativas que apresentaram níveis de correlação significativos, que são: percentual de aparições negativas na Gazeta do Povo, projetos de utilidade pública apresentados, autorizatórios, municipais, estaduais e percentual de votos regionais em 2002. No

“categoria de votação” foi substituída por "percentual de votos regionais”. 
segundo modelo, a variável dependente "Percentual de Votos Regionais em 2002" é testada com as variáveis explicativas de produção legislativa individual: percentual de projetos de utilidade pública, homenagens, autorizatórios, projetos com abrangência municipal, regional, individual e geral; percentual de projetos aprovados e rejeitados. Foram mantidas no modelo apenas as variáveis explicativas que apresentaram resultados estatisticamente significativos.

No primeiro modelo (ver o Quadro 12), montado a partir de seis variáveis explicativas, identi- fica-se o percentual de votos regionais em 2002 como a única variável com resultados significativos para explicar o total de votos obtidos naquele ano, com um coeficiente Beta não padronizado de 535,16 , ou seja, para cada percentual de acréscimo de voto regional no modelo, obtêm-se 535 votos a mais. Todas as demais variáveis de atividade parlamentar mostraram-se não significativas para a explicação do total de votos. Esse resultado comprova a importância da regionalização eleitoral do candidato para maximizar o número de votos obtidos.

QUADRO 12 - COEFICIENTE DE REGRESSÃO LINEAR ENTRE TOTAL DE VOTOS EM 2002 E VARIÁVEIS CORRELACIONADAS

\begin{tabular}{|l|c|c|c|c|}
\hline & $\begin{array}{c}\text { COEFIGIE HTE HÄO } \\
\text { PADROHIZADO }\end{array}$ & $\begin{array}{c}\text { COEFICIENIE } \\
\text { PADROHIZADO }\end{array}$ & T & SIG. \\
\cline { 2 - 6 } & B & BETA & & \\
\hline Percentual de votos regionais em 2002 & 535,166 & 0,678 & 4,300 & 0,000 \\
\hline
\end{tabular}

FONTE: Núcleo de Pesquisa em Sociologia Política Brasileira (s/d).

NOTA: variável dependente: total de votos em 2002.

Considerando que o percentual de votos regionais tem impacto direto no total de votos obtidos pelo candidato à reeleição e que nenhuma outra variável relacionada à produção legislativa apresenta-se estatisticamente significativa, é preciso identificar se o tipo de produção legislativa individual tem importância na regionalização eleitoral, pois, se sim, a produção legislativa passará a contar com impacto indireto sobre o total de votos, já que interfere na regionalização destes. Caso contrário, não é possível afirmar que exista alguma relação empiricamente constatável entre o que o Deputado faz no Parlamento e o seu desempenho eleitoral.

O Gráfico 1 representa a relação entre o número de votos considerados regionais com o total de votos obtidos pelos parlamentares. Pode-se perceber que o alto coeficiente de regressão indicado no Quadro 12 é facilmente identificado pela distribuição dos casos em torno da curva de regressão, que reafirma o alto grau de relação entre as duas variáveis, ou seja, a votação regionalizada tem impacto direto na possibilidade de reeleição do Deputado. No Gráfico, os grupos de parlamentares reeleitos são representados pela cor vermelha e os não-reeleitos pela verde, permitindo identificar também a localização majoritária de cada grupo dentro da distribuição como um todo. Como era de se esperar, os deputados não-reeleitos concentram-se mais próximos da base dos dois eixos do Gráfico, enquanto os reeleitos estão distribuídos ao longo de toda a reta da regressão linear.

\section{GRÁFICO 1 - DISTRIBUIÇÃO ENTRE VOTOS REGIONAISE TOTAIS}

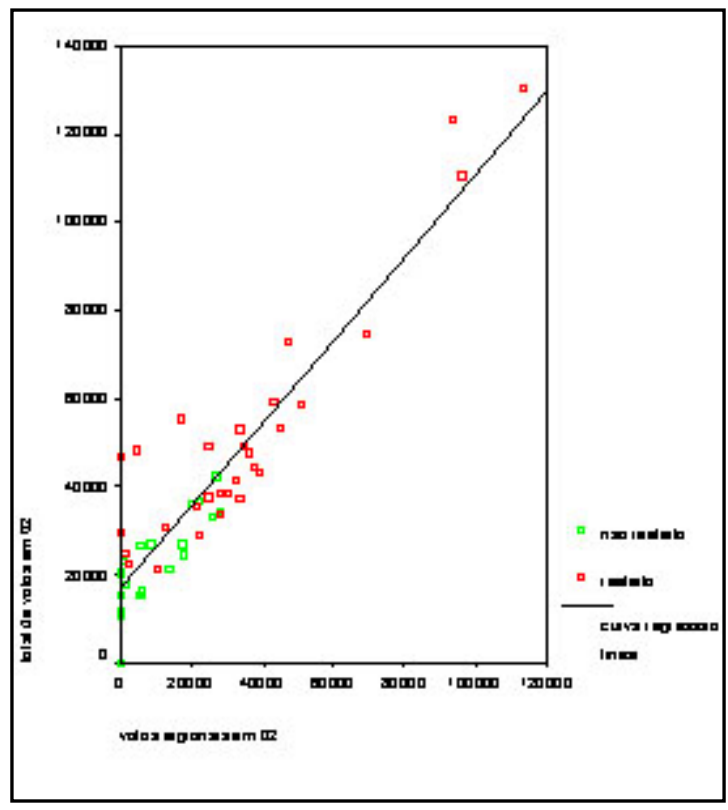

FONTE: Núcleo de Pesquisa em Sociologia Política Brasileira $(\mathrm{s} / \mathrm{d})$. 
O modelo de regressão linear seguinte visa identificar as variáveis que interferem na votação regional do parlamentar, visto que esta é capaz de explicar o total de votos. Foram incluídas nove variáveis de produção parlamentar. Os coeficientes indicam que apenas duas delas apresentam resultados estatisticamente significativos para a regressão com "percentual de votos regionais em 2002”, conforme mostra o Quadro 13. São elas o "percentual de projetos de lei com abrangência municipal" e "percentual de projetos de lei de abrangência regional”, ambos positivos, indicando que para cada percentual a mais de votos regionais obtidos foram necessários 0,843 por cento e 0,876 por cento a mais de projetos municipais e regionais, respectivamente. Isso é suficiente para indicar que os deputados que apresentaram mais projetos de lei de abrangência local, seja municipal ou regional, conseguiram obter um maior percentual de votos regionalizados ao final da legislatura, quando se candidataram à reeleição.

QUADRO 13-REGRESSÃO LINEAR PARA VOTOS REGIONAIS

\begin{tabular}{|l|c|c|c|c|}
\hline & $\begin{array}{c}\text { COEFICIENTE NÃO } \\
\text { PADRONIZADO }\end{array}$ & $\begin{array}{c}\text { COEFICIENTE } \\
\text { PADRONIZADO }\end{array}$ & T & SIG. \\
\cline { 2 - 4 } & B & BETA & & \\
\hline Percentual de projetos municipais & 0,843 & 0,569 & 2,713 & 0,010 \\
Percentual de projetos regionais & 0,876 & 0,304 & 2,093 & 0,043 \\
\hline
\end{tabular}

FONTE: Núcleo de Pesquisa em Sociologia Política Brasileira (s/d).

NOTA: variável dependente: porcentual de votos regionais em 2002.

Como o modelo anterior indicou grande importância de votação regional em relação ao total de votos, é possível afirmar que indiretamente o tipo de produção legislativa tem impacto nas possibilidades de reeleição. Isso também pode ser percebido na distribuição da relação entre as variáveis que qualificam a produção legislativa individual e o percentual de votos regionalizados.
Conforme demonstra o Gráfico 2, quanto maior o percentual de produção de projetos de lei de abrangência estadual, menores as chances de obtenção de votos regionalizados e, por conseqüência, diminuem-se as possibilidades de reeleição. $\mathrm{O}$ inverso ocorre com o percentual de projetos municipais, que ao crescer é acompanhado pelo número de votos regionais, indicando uma relação direta entre as duas variáveis.

\section{GRÁFICO 2-ABRANGÊNCIA ESTADUAL E VOTAÇÃO REGIONALIZADA}

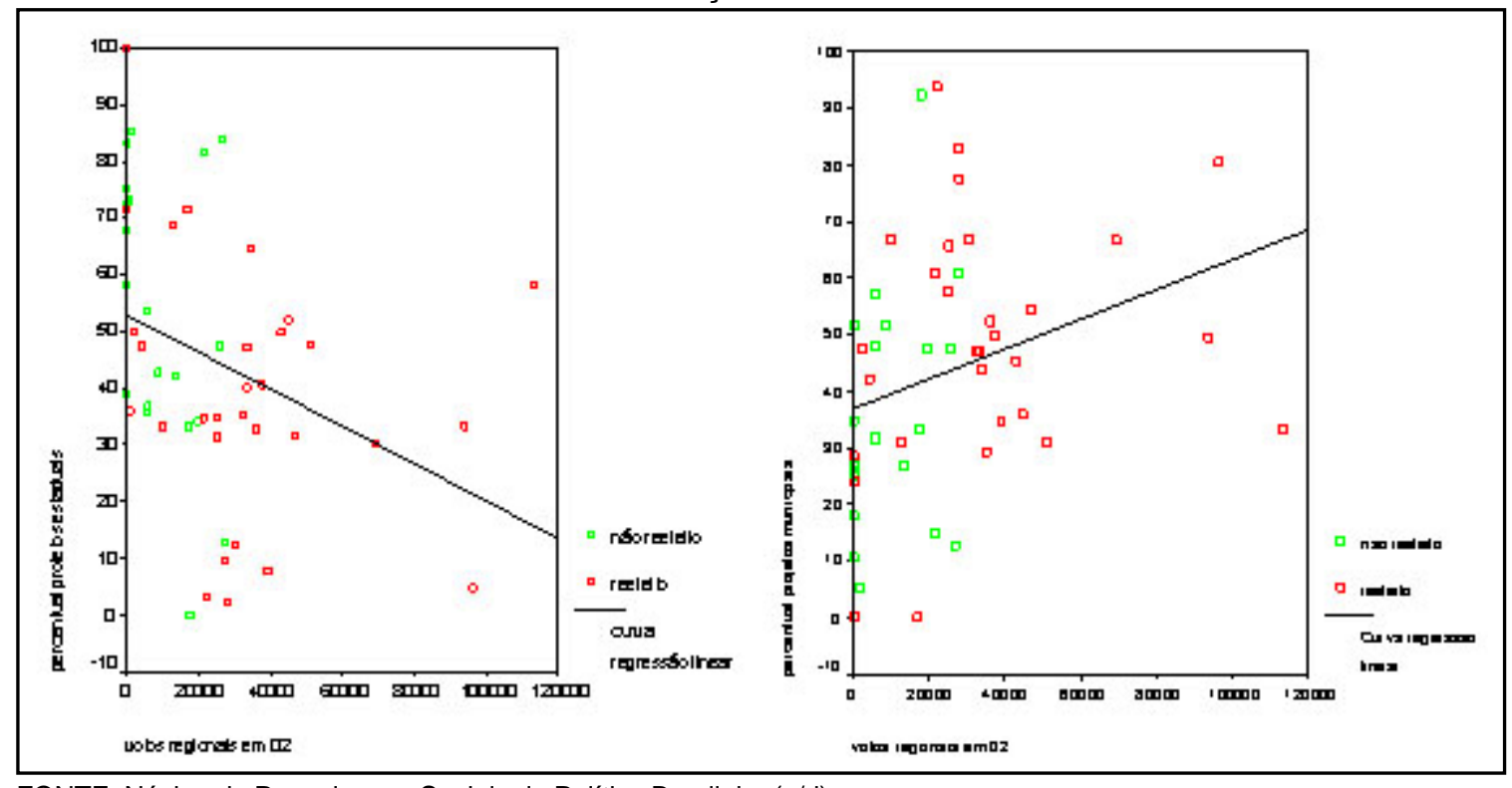

FONTE: Núcleo de Pesquisa em Sociologia Política Brasileira (s/d). 
A mesma relação é percebida quando se compara a abrangência da produção com o total de votos obtidos na eleição de 2002, controlando por tipo de votação (regional, mista ou dispersa). A partir do Gráfico 3 percebe-se, por meio da curva de regressão linear, tratar-se de uma relação positiva entre percentual de projetos de abrangência municipal e total de votos em 2002. O inverso ocorre entre percentual de projetos de abrangência estadual e total de votos, com uma curva negativa. Além disso, os deputados com votação regionalizada tendem a apresentar índices maiores de projetos com abrangência municipal e menores de abrangência estadual, confirmando a hipótese de que a produção individual de determinado tipo de projeto de lei pode beneficiar a votação regionalizada, que é um fator fundamental para a reeleição.

GRÁFICO 3 - DISTRIBUIÇÃO ENTRE PRODUÇÃO LEGISLATIVA POR TOTAL DE VOTOS EM 2002, CONTROLADA POR TIPO DE VOTAÇÃO

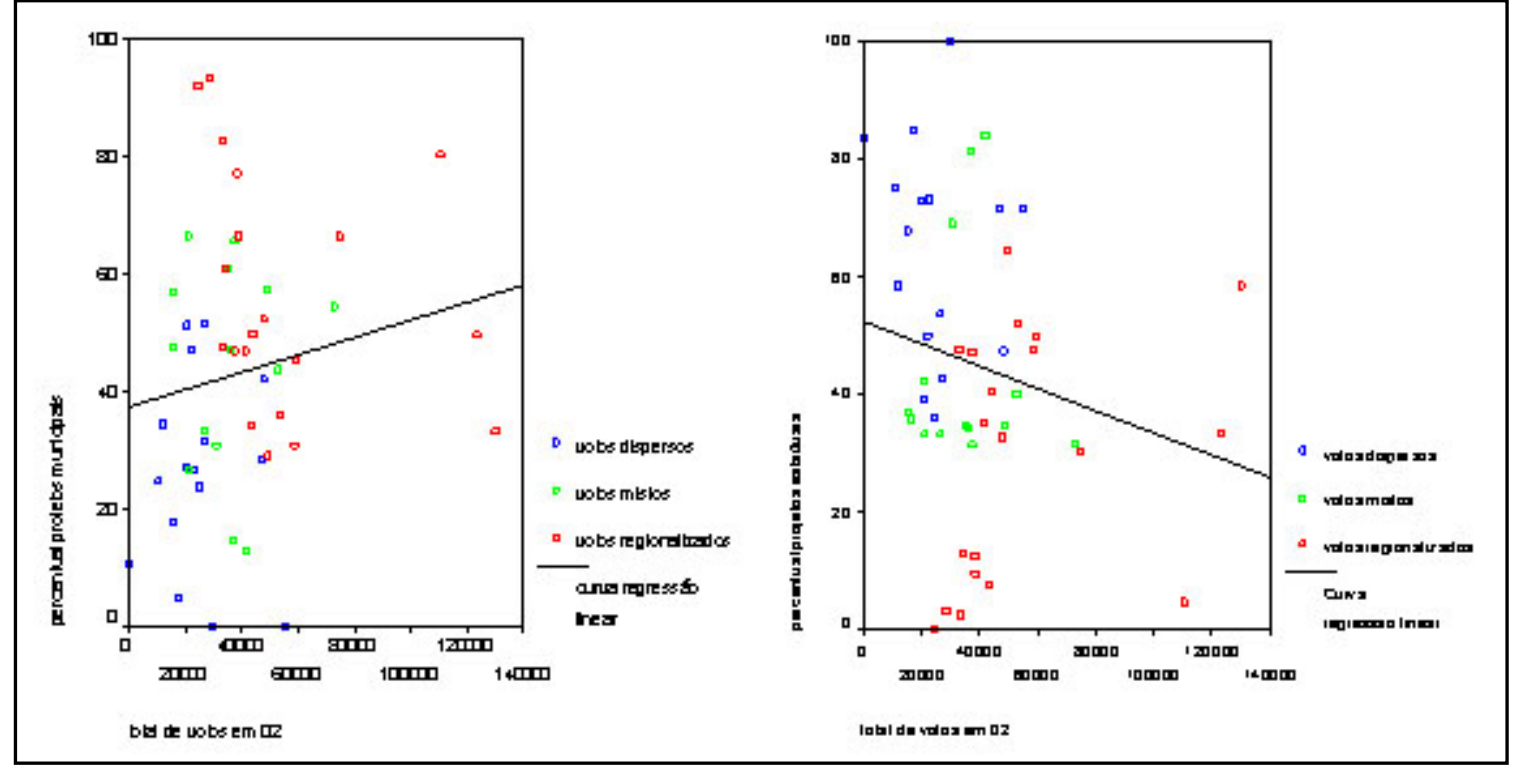

FONTE: Núcleo de Pesquisa em Sociologia Política Brasileira (s/d).

Os resultados dos testes apresentados até aqui mostram a importância da votação regionalizada para a reeleição de deputados estaduais do Paraná em 2002. Assim como nenhuma variável política mostrou-se importante para a reeleição, seja o partido a que pertence o parlamentar, a posição do partido no espectro ideológico e o número de partidos a que o parlamentar pertenceu durante o mandato e coligações eleitorais em 2002. Da mesma forma, as variáveis institucionais, tais como bancada a que pertenceu o parlamentar durante o mandato, ocupação de cargos na mesa executiva e até mesmo posição em relação a temas polêmicos, mostraram-se não significativas estatisticamente para a reeleição do Deputado. Nem mesmo a posição do parlamentar em relação ao projeto de lei que autorizou a privatização da Copel, cerca de um ano antes das eleições, apresentou correlação estatística significativa com o número de votos e se o Deputado foi ou não reeleito em 2002.
Quanto à visibilidade do parlamentar, as variáveis que indicam a quantidade de vezes que o Deputado aparece no principal jornal do estado não apresentam resultados significativos. A única variável significativa é o percentual de citações negativas na Gazeta do Povo, que tem correlação negativa com “reeleição", ou seja, independente do número de vezes que é citado, aquele parlamentar que, ao aparecer, faz-lo em textos com valência negativa, tem menores chances de ser reeleito. O contrário não é verdadeiro, pois o percentual de citações positivas do parlamentar na Gazeta do Povo mostrou-se não significativo para a reeleição.

Quanto à produção legislativa individual, elemento central da análise feita aqui sobre o desempenho em eleições, também não é possível indicar um impacto no número de votos quanto à quantidade de leis individuais apresentadas, percentuais 
de rejeitadas ou aprovadas. Ter produzido mais ou aprovado um número maior de projetos não teve impacto significativo no desempenho eleitoral do parlamentar. Porém, os percentuais de produção legislativa regionalizada, com projetos de abrangência municipal ou regional mostraram-se significativamente correlacionadas com o maior percentual de votos regionalizados. Como esses últimos são relevantes para a reeleição, a produção legislativa segmentada apresenta-se como principal variável explicativa dentre as relacionadas à maior probabilidade de reeleição. Da mesma forma, o percentual de produção de projetos de lei de abrangência estadual apresenta uma correlação negativa com a reeleição.

\section{CONCLUSÕES}

No início deste artigo foram apresentadas as explicações presentes na literatura a respeito da atuação parlamentar, sendo que nelas são feitas relações diretas ou indiretas entre a ação do Deputado ao decorrer do mandato com o objetivo de ser reeleito, ou seja, tendo como meta a obtenção de um número maior de votos. Existe uma oposição identificada entre a atuação parlamentar coerente e leal à bancada ou ao partido político, pois esse tipo de postura em relação a temas controversos que ganham grande visibilidade pode prejudicar a imagem do Deputado junto a seu eleitorado. Considerando a hipótese das duas arenas, seria irracional a atuação parlamentar partidariamente. Porém, estudos mostram que parlamentares brasileiros tendem a ser fiéis às decisões de seus líderes partidários, respeitando as decisões de bancadas nas votações sobre os principais temas, o que poderia gerar um prejuízo ao projeto de reeleição do Deputado.

No entanto, é preciso considerar que o parlamentar pode, além da posição em votações polêmicas, atuar individualmente na representação de seus redutos eleitorais, seja por meio da obtenção de recursos (pork barrel) de políticas públicas implementadas pelo poder Executivo -via emendas orçamentárias, por exemplo; seja por meio da atuação na esfera interna do Legislativo, propondo projetos de leis que atendam a determinados segmentos ou sub-regiões do distrito eleitoral. Isso significa que, independente da atuação em temas de grande visibilidade, coletivamente junto à bancada partidária, o parlamentar também atende regiões específicas com iniciativas do próprio Legislativo.
O objetivo deste trabalho foi testar algumas variáveis que identificam a atuação individual dos deputados estaduais do Paraná com o seu desempenho eleitoral posterior, visando identificar possíveis correlações. Os resultados mostraram que, independente da atuação coletiva do Deputado, aqueles que apresentaram uma produção individual localizada geograficamente, com projetos de lei de abrangência regional ou municipal, por exemplo, tenderam a apresentar melhores chances de reeleição.

O primeiro resultado relevante da análise sobre a $14^{\mathrm{a}}$ Legislatura da ALEP foi que a votação concentrada geograficamente, chamada de votação regional, é um importante fator para a reeleição do parlamentar. Além disso, os dados indicam a existência de uma relação consistente entre o tipo de produção legislativa individual do Deputado e o seu desempenho eleitoral, comprovando que apesar de ser fiel à bancada partidária em relação a temas polêmicos, quando age individualmente apresentando projetos de lei de abrangência social segmentada e abrangência geográfica municipal ou regional, tende a apresentar votações mais localizadas, o que está diretamente relacionado à maior possibilidade de reeleição.

É possível afirmar que, no caso em questão, há uma relação direta entre o tipo de produção parlamentar individual e o comportamento do eleitor. Enquanto deputados candidatos à reeleição que produziram principalmente projetos de abrangência estadual tiveram votos dispersos, deputados com produção localizada apresentaram maiores percentuais de votos regionalizados, indicando uma conexão eleitoral entre as atividades individuais do parlamentar e a aceitação desse trabalho pelas bases eleitorais. Já a conexão entre a atuação coletiva do parlamentar, como em temas polêmicos e de grande interesse do Executivo estadual, não se mostrou tão forte quanto à anterior.

O importante aqui é a identificação do tipo de estratégia individual que trouxe maiores benefícios eleitorais ao candidato à reeleição, já que a atuação coletiva no Parlamento tem baixo impacto na arena eleitoral e nem todos podem contar com a colaboração do poder Executivo na distribuição de pork. Ao final da $14^{\mathrm{a}}$ Legislatura na ALEP, metade dos deputados reeleitos apresentou votação regionalizada, criando na prática uma subdistritalização eleitoral. Dos outros $50 \%$, cerca de metade teve votação mista, ficando entre 
voto regional e disperso. E apenas 23\% do total de reeleitos apresentaram votação dispersa, ou seja, tendo votos em todas as regiões do Paraná, evidenciando que a concentração de votos em determinadas regiões é uma estratégia que resulta em ganhos para o parlamentar que pretende ser reeleito, mas que depende em grande medida da atuação individual do Deputado no poder Legislativo.

Os resultados mostram ser possível aceitar a idéia de uma arena legislativa centralizada, em que a ação parlamentar independente dos desejos prin- cipais de reeleição, e de uma arena eleitoral personalista, como proposta por Pereira e Muller (2003). Mas indicam também a existência, no Parlamento, de uma arena paralela à organizada por partidos fortes que é onde o parlamentar atua individualmente, propondo projetos de lei que dependem exclusivamente de recursos legislativos para atingir diretamente suas bases eleitorais. É quando o parlamentar age independente de sua bancada, visando principalmente atender as demandas de representação de seus eleitores, portanto, tendo como objetivo principal a reeleição.

Emerson Urizzi Cervi (ecervi@brturbo.com.br) é Doutor em Ciência Política pelo Instituto Universitário de Pesquisas do Rio de Janeiro (Iuperj) e Professor na Universidade Estadual de Ponta Grossa (UEPG).

\section{REFERÊNCIAS BIBLIOGRÁFICAS}

AMES, B. 2000. The Deadlock of Democracy in Brazil. Ann Arbor : University of Michigan.

AMORIM NETO, O. \& SANTOS, F. 2001. The Executive Connection : PresidentiallyDefined Factions and Party Discipline in Brazil. Party Politics, v. 7, n. 2, p. 213-234. Disponível em : http://redalyc.uaemex.mx/ redalyc/pdf/218/21844203.pdf. Acesso em : 22.jan.2009.

BOWLER, S. 2000. Parties in Legislature : Two Competing Explanations. In : DALTONS, R. J. \& WATTENBERG, M. P. Parties Without Partisans. New York : Oxford University.

CAIN, B.; FEREJOHN, J. \& FIORINA, M. 1987. The Personal Vote : Constituency Service and Electoral Independence. Cambridge, Mass. : Harvard University.

CAREY, J. \& SHUGART, M. S. 1995. Incentives to Cultivate the Personal Vote : A Rank Ordering of Electoral Formulas. Electoral Studies, v. 14, n. 4, p. 417-440, Dec.

COX, G. 1987. The Efficient Secret. The Cabinet and the Development of Political Parties in Victorian England. Cambridge : Cambridge University.

COX, G. \& MCCUMBBINS, M. 1993.
Legislative Leviathan : Party Government in the House. Berkeley : University of California.

DOWNS, A. 1999. Uma teoria econômica da democracia. São Paulo : USP.

FIGUEIREDO, A. C. \& LIMONGI, F. 2000. Presidential Power, Legislative Organization and Party Behavior in Brazil. Comparative Politics, New York, v. 32, n. 2, p. 151-170.

2002. Incentivos eleitorais, partidos políticos e política orçamentária. Dados, Rio de Janeiro, v. 45, n. 2, p. 303-339. Disponível em : http://www.scielo.br/pdf/dados/v45n2/ 10790.pdf. Acesso em : 19.jan.2009.

MANIN, B. 1995. As metamorfoses do governo representativo. Revista Brasileira de Ciências Sociais, São Paulo, n. 29, p. 5-34. Disponível em : http://www.anpocs.org.br/ portal/publicacoes/rbcs_00_29/ rbcs29_01.htm. Acesso em : 19.jan.2009.

MAYHEW, D. R. 1974. Congressional Elections : The Case of the Vanishing Marginals. Polity, v. 6, n. 3, p. 295-317, Spring.

MENEGHELLO, R. 1998. Partidos e governos no Brasil contemporâneo (19851997). São Paulo : Paz e Terra. 
NICOLAU, J. M. 2002. Como controlar os representantes? Considerações sobre as eleições para a Câmara dos Deputados no Brasil. Dados, Rio de Janeiro, v. 45, n. 2, p. 219236. Disponível em : http://www.scielo.br/pdf/ dados/v45n2/10787.pdf. Acesso em : 19.jan.2009.

PEREIRA, C. \& MUELLER, B. 2003. Partidos fracos na arena eleitoral e partidos for- tes na arena legislativa : a conexão eleitoral no Brasil. Dados, Rio de Janeiro, v. 46, n. 4, p. 734-771. Disponível em : http:// www.scielo.br/pdf/\%0D/dados/v46n4/ a04v46n4.pdf. Acesso em : 19.jan.2009.

SANTOS, W. G. 2002. Votos e partidos. Almanaque de dados eleitorais : Brasil e outros países. Rio de Janeiro : FGV.

\section{OUTRA FONTE}

NUCLEO DE PESQUISA EM SOCIOLOGIA POLÍTICA BRASILEIRA. s/d. Banco de dados do Núcleo de Pesquisas em Democracia e Instituições Políticas. Curitiba : UFPR. Disponível em : http:// www.cis.org.br. Acesso em : 19.jan.2009. 
donné une caractéristique générale, appuyée sur la conception de fin de priviléges, néanmoins sans l'élargissement de la citoyenneté.

Mots-clés : républicanisme ; Paraná ; presse politique ; fédéralisme ; groupe politique.

PRODUCTION LÉGISLATIVE ET CONNEXION ÉLECTORALE DANS L’ASEMBLÉE LÉGISLATIVE DE L'ÉTAT DU PARANÁ

\section{Emerson Urizzi Cervi}

L'article intègre les travaux portant sur les relations entre l'arène politique législative et l'arène politique électorale, dénommées « connexion électorale ». L'objectif est d'analyser les interactions entre ces deux arènes dans un système de représentation politique sous-national : le législatif de l'état du Paraná. À partir de cette relation entre la production législative individuelle des députés dans la 14ème législature de l'Asemblée Législative de l'État du Paraná (ALEP) et la performance électorale de ceux qui disputent la réélection, on cherche à identifier des éventuels résultats électoraux des candidats à la réélection. À cet effet, outre les résultats électoraux des candidats à la réélection, qui ont donné naissance à une typologie du vote (aussi bien concentrée ou non concentrée au niveau de la région) comme variable dépendante, trois ensembles de variables explicatives sont compris dans le modèle. Le premier est formé des variables sur la position politique institutionalisée (groupe auquel on appartient ; idéologie ; parti politique ; exercice de fonction auprès de la présidence de l'assemblée ; nombre de mandats à l'ALEP ; et position à l'égard de thème polémique). Le second porte sur la visibilité du mandat (nombre d'apparitions des parlementaires dans le principal journal quotidien de l'État et genre d'apparition). Le troisième groupe de variables explicatives concerne la production législative individuelle (type de projet de loi proposé ; portée géographique du projet de loi ; portée sociale du projet de loi ; nombre de projets proposés ; et nombre de projets adoptés pendant le mandat). À partir de l'intersection des variables composant le modèle en tests d'indépendance de moyennes et de regressions, le modèle analytique montre que l'existence d'un grand rapport entre les votes concentrés dans la région et une plus grande probabilité de réélection. Les variables explicatives sur la position politique et la visibilité du mandat se sont avérées faibles en ce qui concerne l'explication pour le type de vote, alors que certaines variables sur la production législative individuelle ont présenté un taux élevé de rapport avec le vote régional et, par conséquent, avec une plus grande possibilité de réélection du parlementaire.

MOTS-CLÉS : connexion électorale ; députés de l’état ; production législative ; état du Paraná. 
constitutional rights and ample recourse to incarceration. In this vein, our contemporary democratic governments have frequently adopted a punitive stance that seeks to reaffirm the State's aptitudes for punishing and controlling criminality.

KEYWORDS: penal control; incarceration; democratic tutelage; punitive State; Sociology of Violence.

\section{POLITICAL JOURNALISM AND REPUBLICAN THOUGHT IN LATE $19^{\mathrm{TH}}$ CENTURY} PARANÁ

\section{Amélia Siegel Corrêa}

The crisis of the Brazilian monarchical regime was accompanied by the emergence and expansion of the republican movement at the end of the 19th century. During that period, the press not only became the stage of institutional debates but also had the role of an informal power, linked to the government and political party organization. It was a press that expressed opinions and created a space for partisan commentary. Newspaper columns were used to anonymously air that which could not be expressed publicly in the Legislative Assembly, the Senate or the House of Representatives, thus constituting an alternative tribune for debate. This article seeks to give voice to the different republican models that circulated within these state of Paraná newspapers, relating them to the configurations they were a part of and with the position that they held within local and national fields of power. Furthermore, it is important to recognize that the dominant republican ideas were not disseminated without resistance: rather, they were heard and combated at the local level, although efforts in this regard remained lacking in political force. Our analysis incorporates the Bourdieusian perspective according to which discourses are not only signs to be understood and decoded but also status indicators - seeking to be validated and evaluated - and forms of authority, seeking to be believed and obeyed; in both cases, object of struggles over symbolic power. Analysis of republican discourse shows that Paraná state politics of the late 19th century was more a result of alliances and tensions between groups than the fruit of clear ideological stands. Discourses served mostly as rhetorical weapons which were used to orient intra-elite conflict, moved by the desire for participation. This gave them a generic character, based on a notion of putting an end to privilege without widening citizenship rights..

Keywords: Republicanism; Paraná state; political journalism; federalism; political field.

\section{LEGISLATIVE PRODUCTION AND ELECTORAL CONNECTION IN THE PARANÁ STATE LEGISLATIVE ASSEMBLY}

\section{Emerson Urizzi Cervi}

This article belongs to a field of work that deals with the relationships between the legislative political arena and electoral politics, relations that have been referred to as "electoral connection". Our goal is to analyze the interaction between these two arenas within a system of sub-national political representation: the Paraná state legislature. Through looking at the relationship between the individual legislative action of state representatives within the 14th legislative period of the Paraná State Legislative Assembly (Assembléia Legislativa do Paraná (ALEP)) and the legislative performance of those who ran for re-election we seek to identify possible interdependence between individual parliamentary activity and re-election. For these purposes, in addition to putting together a voting typology on electoral results for candidates seeking re-election (looking at whether voting is regionally concentrated or not as dependent variable), our model also includes three sets of explanatory variables. The first is made up of variables regarding institutionalized political position (parliamentary group affiliation, ideology, political party, position occupied within the legislature, number of ALEP mandates served and position on polemic issues). The second looks at the visibility of the mandate (number of 
times that representatives appear in the most important state daily newspaper and context in which he or she appears). The third group of explanatory variables has to do specifically with individual legislative activity (type of bills proposed, geographic scope of proposal, number of bills proposed, number of projects approved during the mandate.) Through looking at the relationship between the different variables that make up the model in tests for interdependence or regression, our analytic model reveals the existence of a strong correlation between regionally-concentrated voting and chances of re-election. Explanatory variables on political position and mandate visibility have a weak ability to explain type of voting, whereas some variables on individual legislative production have revealed a high degree of correlation with regionalized voting and, therefore, with enhanced chances for re-election.

KEYWORDS: electoral connection; state representatives; legislative action; state of Paraná. 